\title{
BESI DALAM AL QUR'AN DAN SAINS KIMIA (ANALISIS TEORITIS DAN PRAKTIS MENGENAI BESI DAN UPAYA MENGATASI KOROSI PADA BESI)
}

\author{
Tety Sudiarti ${ }^{1 *}$, Gina GifTIA A. Delilah ${ }^{1}$, Rohmanur AzIZ $^{2}$ \\ ${ }^{1}$ Jurusan Kimia, Fakultas Sains dan Teknologi, UIN Sunan Gunung Djati Bandung, \\ Jl. A. H. Nasution No. 105 Cibiru Kota Bandung \\ ${ }^{2}$ Jurusan Pengembangan Masyarakat Islam, Fakultas Dakwah dan Komunikasi, UIN Sunan Gunung \\ Djati Bandung, Jl. A. H. Nasution No. 105 Cibiru Kota Bandung \\ *alamat email korespondensi: tety.sudiarti@uinsgd.ac.id
}

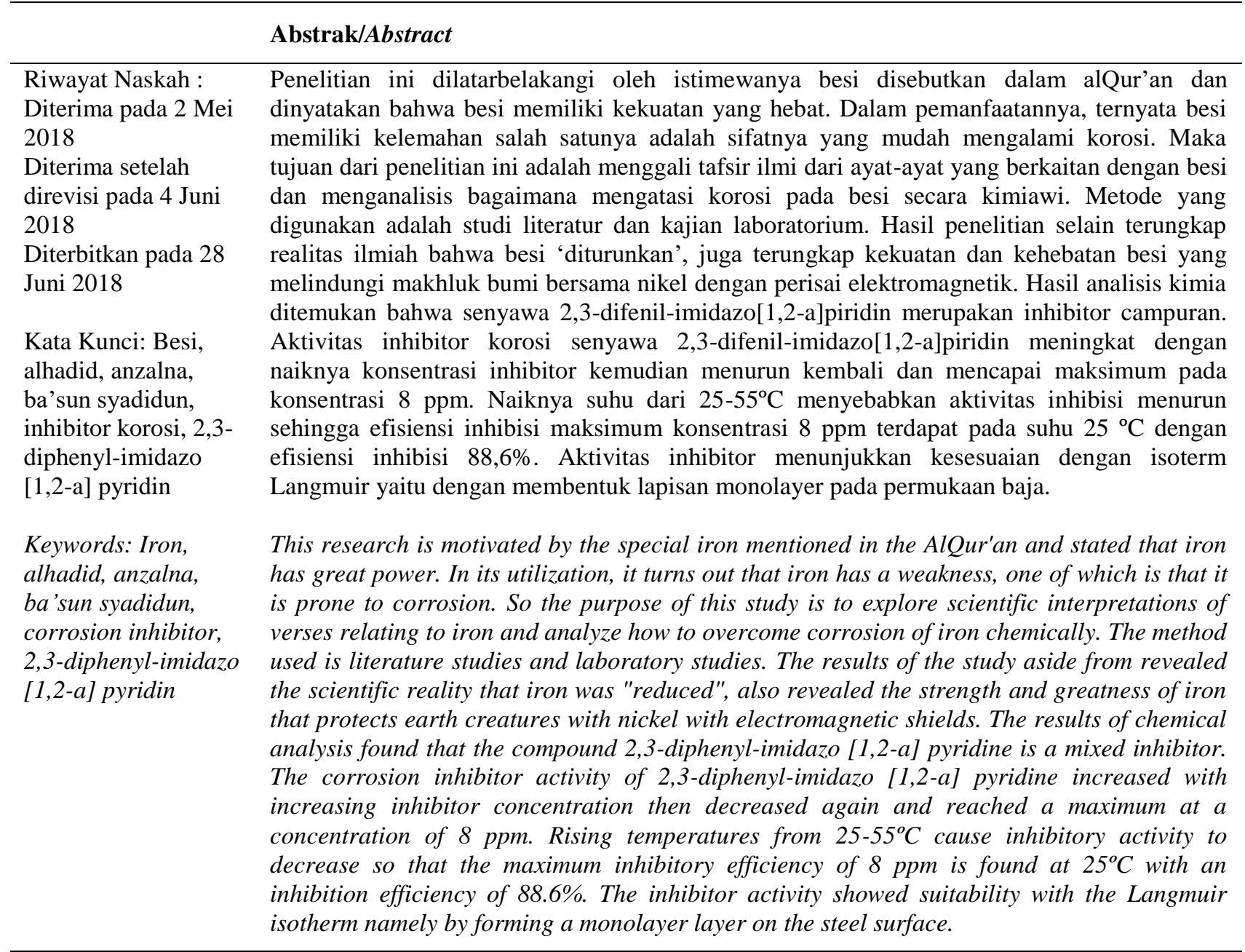

\section{PENDAHULUAN}

Bukti tentang kebenaran al Qur'an tidak terbantahkan lagi dan hal ini menimbulkan ketertarikan para ilmuan untuk membuktikan al Qur'an secara ilmiah dengan mengkaji ayat-ayat kauniyah terutama berkaitan dengan fenomena materi. Salah satu fenomena itu adalah besi yang menjadi nama salah satu surat ke 57 dalam al Qur'an dan disebutkan dalam ayat ke 25. “... Dan Kami ciptakan besi yang padanya terdapat kekuatan yang hebat dan berbagai manfaat bagi manusia, (supaya mereka mempergunakan besi itu) dan supaya Allah mengetahui siapa yang menolong (agama)-Nya dan rasul-rasul-Nya padahal Allah tidak dilihatnya. ...". Dalam ayat tersebut digambarkan bahwa besi memiliki kekuatan yang disebutkan oleh Allah dengan kekuatan yang hebat (syadid) dan banyak manfaatnya untuk manusia.

Di dalam al Qur'an dinyatakan bahwa "pada besi terdapat kekuatan yang hebat" lalu dikaitkan dengan kajian- kajian sains terutama kimia dan fisika, kita menemukan beberapa hal yang seolah-olah bertolak belakang. Jika ditinjau dari sifat fisik, besi bukan merupakan unsur yang paling keras, karena masih banyak logam lain yang lebih keras dari besi dan unsur logam yang 
paling keras adalah intan (salah satu alotrof karbon). Demikian juga titik leleh besi $\left(1538^{\circ} \mathrm{C}\right)$, masih jauh di bawah logam yang paling tinggi titik lelehnya, yakni tungsten $\left(3422^{\circ} \mathrm{C}\right)$. Jika ditinjau dari sifat kimia, besi adalah logam yang sangat mudah berkarat dan kalah dibanding tembaga. Besi juga mudah teroksidasi karena potensial reduksinya cukup negatif [1]

Selama penggunaannya besi juga dapat mengalami kerusakan yang dipicu oleh kondisi lingkungan yang disebut dengan korosi. Korosi adalah proses degradasi suatu material karena reaksi kimia, khususnya reaksi elektrokimia dengan lingkungan yang meliputi udara, suhu, kelembaban, tingkat pencemaran serta keberadaan zat-zat kimia yang bersifat korosif.

Adapun upaya untuk mencegah terjadinya kerusakan pada besi yang diakibatkan oleh korosi dapat dilakukan dengan pelapisan pada permukaan logam, perlindungan katodik, penambahan inhibitor korosi, dan lain-lain. Dari beberapa cara tersebut, inhibitor korosi merupakan metode yang paling praktis dan mudah dilakukan serta biaya yang dibutuhkan relatif rendah untuk menghambat terjadinya korosi. Inhibitor korosi dapat didefinisikan sebagai suatu zat yang apabila ditambahkan dalam jumlah sedikit ke dalam lingkungan akan menurunkan serangan korosi lingkungan terhadap logam.

Dengan latar belakang inilah maka menarik untuk diteliti, bagaimana realitas besi dalam kajian qur'aniyah dan kauniyah. Kajian ini membantu kita untuk semakin memahami mengapa penyebutan besi begitu istimewa dalam al Qur'an dan disebutkan 'memiliki kekuatan yang hebat' serta sebagai upaya agar manusia bisa memaksimalkan pemanfaatan besi dalam kehidupanya sesuai isyarat al Qur'an.

\section{EKSPERIMEN}

\section{Material}

Bahan-bahan yang akan digunakan untuk sisntesis inhibitor dalam penelitian ini adalah 2fenilasetofenon, 2-aminopiridin, I2, $\mathrm{NaOH}$, $\mathrm{CH}_{2} \mathrm{Cl}_{2}$, aqua DM, anhidrat $\mathrm{Na}_{2} \mathrm{SO}_{4}$, heksana, kertas saring Whatmann (no. 40) dan pelat kromatografi lapis tipis silika alumina. Adapun untuk menguji laju korosi digunakan bahan sebagai berikut :

\section{Larutan Uji}

Larutan uji yang digunakan adalah $100 \mathrm{~mL}$ larutan $\mathrm{NaCl} 1 \%$ jenuh $\mathrm{CO}_{2}$ yang berperan sebagai medium korosif.

\section{Inhibitor}

Senyawa inhibitor yang digunakan adalah senyawa 2,3-difenil-imidazo[1,2-a]piridin.

\section{Instrumentasi}

Untuk kajian laboratorium, alat-alat yang akan digunakan untuk sintesis inhibitor meliputi peralatan gelas standar Laboratorium kimia, spatula, botol semprot, neraca analitik, pipet tetes, labu, satu set alat refluks, dan thermometer.

Untuk karakterisasi pada tahap hasil akhir sintesis digunakan uji titik leleh menggunakan alat Stuart Scientific Melting Point Apparatus SMP 2, dan spektroskopi infra merah (Perkin Almer Spektrum One FTIR). Untuk penentuan laju korosidalam penelitian ini, peralatan yang digunakan yaitu peralatan radiometer Voltalab ${ }^{\circledR}$ tipe PGZ301, program software Voltamaster dan sel elektrokimia tiga elektroda yaitu elektroda kalomel jenuh, elektroda kerja dan elektroda platina. Elektroda kerja yang digunakan yaitu baja karbon yang dibuat dengan bentuk lempengan dan berpenampang lingkaran dengan luas permukaan $1,13 \mathrm{~cm}^{2}$. Elektroda baja karbon ini dalam metoda kerjanya disekat oleh perekat araldite dan politetrafluoroetilen. Elektroda kalomel jenuh (SCE) sebagai elektroda referensi dan elektroda platina sebagai elektroda pembantu. Elektoda kerja (baja karbon) dan elektroda platina dipasang saling berhadapan.

\section{Prosedur}

Untuk mengkaji tentang konsep besi dalam al Qur'an dan ilmu kimia, baik penyebutan, sifat, dan kegunaannya, maka dilakukan studi literatur dari kitab, buku, jurnal, dan internet lalu dilakukan penelaahan dan analisis.

Untuk mengetahui aktivitas senyawa 2,3difenil-imidazo[1,2-a]piridin sebagai inhibitor korosi besi (baja karbon) dalam larutan elektrolit jenuh karbon dioksida,langkah pertama adalah preparasi sampel baja karbon. Sebelum digunakan, permukaan baja dihaluskan dengan ampelas silicon karbida (grade 600-1200) dan dibilas dengan air bidestilat.Kemudian pembuatan larutan uji $\mathrm{NaCl} 1 \%$ yang berperan sebagai medium korosif, serta ditambahkan larutan inhibitor dengan berbagai variasi konsentrasi. Inhibitor yang digunakan yaitu senyawa 2,3-difenilimidazo[1,2-a]piridin yang dilarutkan dan diencerkan dengan metanol hingga 1000 ppm. Untuk pengukuran dengan variasi konsentrasi, larutan inhibitor ditambahkan ke dalam larutan $\mathrm{NaCl} 1 \%$ masing-masing sebanyak $0,8 \mathrm{~mL}(8$ ppm); 1,6 mL (16 ppm); 2,4 mL (24 ppm) 
sampai menjadi $100 \mathrm{~mL}$ larutan uji. Larutan uji dijenuhkan dengan mengalirkan gas $\mathrm{CO}_{2}$ selama 30 menit untuk menghilangkan $\mathrm{O}_{2}$ yang terlarut. Kemudian dilakukan pengukuran elektrokimia dengan metode ekstrapolasi Tafel dalam rentang potensial $-50 \mathrm{mV}$ dan $50 \mathrm{mV}$.Untuk pengukuran aktivitas inhibisinya dilakukan uji korosi menggunakan metode ektrapolasi Tafel dengan variasi konsentrasi dan suhu pada rentang suhu $25^{\circ} \mathrm{C}$ sampai $55^{\circ} \mathrm{C}$. Penentuan laju korosi dilakukan untuk mengetahui pengaruh struktur molekul dan [1] gugus fungsi dari inhibitor yang akan digunakan.

\section{Pengaruh Konsentrasi Inhibitor}

Untuk mengetahui pengaruh konsentrasi inhibitor dibuat larutan uji dengan menggunakan larutan $\mathrm{NaCl} 1 \%$. Inhibitor yang digunakan berupa gel yang kemudian dilarutkan dan diencerkan dengan metanol hingga $1000 \mathrm{ppm}$. Konsentrasi inhibitor divariasikan dengan kenaikan rata-rata 8 ppm.

\section{Pengaruh Suhu}

Untuk menentukan pengaruh suhu terhadap efektifitas inhibitor dalam korosi baja karbon di lingkungan elektrolit jenuh karbon dioksida dilakukan variasi suhu larutan uji pada $25^{\circ} \mathrm{C}$, $35^{\circ} \mathrm{C}, 45^{\circ} \mathrm{C}, 55^{\circ} \mathrm{C}$.

\section{HASIL DAN PEMBAHASAN}

\section{Tinjauan Tafsir Surat Al Hadid ayat 25}

Terdapat beberapa pandangan para mufassir terkait hakikat besi sebagaimana yang disebutkan dalam surat al Hadid (57): 25 terutama penekanannya pada ayat yang berbunyi 'waanzalnal hadiida'.

Syaikh Makhluf dalam kitab Shafwatul Bayan Li Ma'anil Qur'an (1956) menafsirkan ayat 'waanzalnal hadiida' dengan "dan Kami menciptakan besi untuk kalian'. Ayat ini sama dengan firman Allah SWT dalam Q.S. Az Zumar ayat 6 'waanzala lakum minal an'aami tsamaaniyata azwaaj' 'Dan Dia telah menurunkan untuk kalian dari binatang ternak dengan delapan pasang'. Yakni, Kami sediakan besi untuk kalian dan itu sebagai nikmatNya untuk kalian semua. Kami juga ajarkan kalian tatacara mengeluarkannya dari perut bumi dan Kami ilhamkan pula cara mengelolanya. Ayat 'fiihi ba'sun syadiidun' berarti 'padanya terdapat kekuatan yang hebat'. Hal ini menurutnya adalah seperti tameng dan pedang serta berbagai amunisi peperangan dan lainnya.

Menurut Abu Hayyan dalam Kitab Tafsir Al Bahru Al Muhith (t.t.) bahwa Allah mengungkapkan keberadaan besi dengan kata 'diturunkan' sebagaimana pada firman-Nya 'waanzala lakum minal an'aami tsamaaniyata azwaaj', karena semua perintah dan segala urusan serta hukum ketika dilempar dari langit maka ia akan jatuh semua dari atas. Disini Allah menghendaki besi berasal dari jenis barang tambang.

As-Shobuni dalam kitab Shofwatut Tafasir (2005) berpendapat bahwa 'waanzalnal hadiida fiihi ba'sun syadiidun' yakni 'Kami ciptakan dan adakan besi yang memiliki kekuatan dahsyat'. Itu karena peralatan perang diambil dari besi, seperti misalnya baju besi, panah, busur dan lainnya. Besi memberikan manfaat yang sangat besar bagi kehidupan manusia bahkan setiap produksi dapat dipastikan menggunakan besi sebagai alatnya.

Dalam Kitab Tafsir al Qur'an al Adzim Ibn Katsir menulis (Dar ihya al kutub al arabiyah, Cairo : t.t.): Firman Allah: wa anzalnaa hadiida fiiHi ba'sun syadiidun ("Dan Kami ciptakan besi yang padanya terdapat kekuatan yang hebat.") maksudnya, Kami telah membuat besi untuk menekan orang-orang yang menolak kebenaran dan menentangnya setelah hujjah disampaikan kepada mereka. Oleh karena itu Rasulullah saw. menetap di Makkah setelah mendapatkan risalah kenabian selama tigabelas tahun, selama itu telah diwahyukan kepada beliau surah-surah Makkiyyah yang semua itu merupakan bantahan terhadap orang-orang musyrik, penerangan dan penjelasan mengenai tauhid sekaligus sebagai bukti.

Setelah hujjah ditegakkan bagi orang-orang yang menentang, Allah mensyariatkan hijrah dan memerintahkan mereka berperang dengan pedang, memenggal batang leher, dan terhadap siapa saja yang menentang, mendustakan dan membangkang terhadap al-Qur'an serta mendustakannya.

Ahmad dan Abu Dawud telah meriwayatkan dari Ibnu 'Umar, ia bercerita: Rasulullah saw. bersabda: "Aku diutus dengan membawa pedang sebelum hari kiamat datang, sehingga hanya Allah saja yang diibadahi, tiada sekutu bagi-Nya. Dan dijadikan rizkiku berada di bawah naungan tombakku, serta dijadikan kehinaan dan kerendahan ada pada orang-orang yang menentang perintahku. Dan barangsiapa menyerupai suatu kaum, berarti ia termasuk golongan mereka."

Oleh karena itu Allah berfirman: fiihi ba'sun ("yang padanya terdapat kekuatan yang hebat") yakni persenjataan, seperti pedang, 
tombak, lembing, baju besi dan lain-lain. Wa manaafi'u linnaasi ("dan berbagai manfaat bagi manusia.") yakni dalam kehidupan mereka, seperti [bahan membuat] mata bajak, kampak, beliung, gergaji dan alat-alat tenun, berladang, memasak, membuat roti dan apapun yang manusia tidak akan dapat beraktifitas kecuali dengan menggunakan alat tersebut.

Muftie menyatakan bahwa mufassir klasik tidak manafsirkan waanzalnal hadiida dengan 'Kami turunkan besi', sebagaimana terjemahan 'Kami turunkan bersama mereka al Kitab dan mizan (keadilan, keseimbangan, keselarasan, kesepadanan). Analisanya adalah karena pada saat itu tidak terbayangkan dalam fikiran para mufasir klasik bagaimana caranya besi diturunkan dari langit [2].

Beberapa terjemahan Q.S. Al Hadid (57) : 25 menunjukkan adanya dua perbedaan kelompok terjemahan pada kalimat tersebut yaitu 'menciptakan/menjadikan' dan 'menurunkan'. Yunus dalam tafsirannya menjelaskan bahwa "bukanlah arti ayat ini bahwa Allah menurunkan besi dari langit, melainkan mengadakannya dalam bumi dan menganugerahkan akal pikiran kepada manusia untuk mengeluarkannya sehingga dapat dipergunakan untuk kekuatan dalam medan peperangan". Menurutnya, seolah-olah Allah telah salah menggunakan kata 'anzalna' pada besi. [3].

Begitu pula Shihab berpendapat bahwa anzalna/ diturunkan digunakan juga oleh al Qur'an dalam arti menciptakan atau menampakkan sesuatu yang tadinya tidak tampak. Kedelapan jenis ternak dalam Q.S. Az Zumar (39) : 6) dilukiskan penciptaannya dengan kata tersebut dan turunnya al Qur'an dipahami oleh banyak ulama dalam arti ditampakkannya kalam Ilahi itu di alam raya.

Secara tekstual tidak ada pengaruh yang signifikan dari perbedaan terjemahan terhadap makna atau isi ayat secara keseluruhan, tetapi bagi para ilmuan saintis hal ini menarik untuk diamati dan dikaji dari sudut ilmu yang lain sehingga ditemukan hikmah dan pemahaman secara sains tentang mengapa besi sangat spesial penyebutannya dalam al Qur'an dan pada akhirnya semakin menguatkan keyakinan terhadap Allah swt.

Mengapa Allah menggunakan kata 'waanzalnaa' (dan Kami turunkan)" bukan "waja'alnaa (dan Kami jadikan/ciptakan)" atau waakhrajnaa (dan Kami keluarkan)? Penggunaan kata "anzalnaa" untuk besi sepadan dengan kata "anzalnaa" yang digunakan untuk air yang diturunkan dari langit dan juga kata "anzalnaa" untuk al Qur'an yang diturunkan kepada umat manusia melalui Nabi Muhammad saw. Untuk menjawab hal ini kita tidak dapat memahaminya apabila hanya dari satu bidang ilmu tertentu saja, karena begitu luasnya ilmu Allah.

\section{Kajian Ilmiah Alhadid}

\section{Tafsir ilmi Q.S. Alhadid ayat 25}

Dalam al Qur'an, alhadid adalah nama salah satu surat ke 57. Nama alhadid diambil dari ayat ke 25, waanzalnal hadida.

Ada dua point yang dalam Q.S. Al Hadid ayat 25 ini yang menarik untuk dikaji secara ilmiah, sehingga bisa memberi pemahaman yang lebih luas mengapa penyebutan besi begitu istimewa di dalam al Qur'an. Pertama adalah kalimat, waanzalnal hadiida dan yang kedua adalah kalimat fiihi ba'sun syadiidun.

Pertama, Anzala merupakan fi'il wazan af'ala dari nazala (turun-menurunkan). Ba'sun (keberanian, kekuatan), syadidun jamak taksir asysyidd'u-syidadun-syududun (yang berani, yang keras, yang kuat). Manafi'un adalah jamak taksir dari manfa'atun, isim dari nafa'a-yanfa'u-naf'an (bermanfaat, berguna).

Waanzalnal hadida, akan sulit difahami jika kita langsung mengaitkannya dengan barang keseharian yang berkaitan dengan besi. Bagaimana pagar besi, tiang listrik dan lain sebagainya diturunkan langsung dari langit? Begitu pula akan sulit dipahami jika kemudian dikaitkan dengan ayat besi yang lain seperti Q.S. Saba (34) ayat 10-11:

Dan Sesungguhnya telah Kami berikan kepada Daud kurnia dari kami. (kami berfirman): "Hai gunung-gunung dan burung-burung, bertasbihlah berulang-ulang bersama Daud", dan Kami telah melunakkan besi untuknya (10); (yaitu) buatlah baju besi yang besar-besar dan ukurlah anyamannya; dan kerjakanlah amalan yang saleh. Sesungguhnya aku melihat apa yang kamu kerjakan.

Besi dalam surat Saba tersebut disebutkan dengan baju besi yang besar-besar. Maka akan semakin sulit untuk memahami bagaimana besi yang besar itu diturunkan dari langit. Kesulitan ini mendorong dibuatnya terjemah Al Qur'an dalam pemahaman yang lebih sesuai pada saat itu, yaitu 'Dan Kami ciptakan besi'. Terjemahan ini sesungguhnya terdengar ganjil, karena anzalna digunakan dua kali di dalam ayat ini, yang pertama wa anzalna ma'ahumul kitab diterjemahkan secara harfiah 'dan Kami turunkan bersama mereka kitab'. Apabila konsisten, anzala selanjutnya waanzalnal hadida bisa diterjemahkan menjadi 'dan Kami menurunkan besi', bukan 'dan Kami menciptakan besi'. Karena menciptakan, 
menjadikan atau membuat berasal dari kata khalaqa, ja'ala atau shona'a bukan nazala yang berarti turun. Penggunaan terjemah penurunan besi akan memberi konsekuensi hancurnya bangunan bahkan melukai manusia [4].

Ketika kata "anzalna," dalam ayat ini diterjemahkan dengan 'kami turunkan', maka seolah-olah memiliki arti kiasan untuk menjelaskan bahwa besi diciptakan untuk memberi manfaat bagi manusia. Namun ketika kita mempertimbangkan makna harfiahnya yaitu 'secara fisik diturunkan dari langit', kita akan menyadari bahwa ayat ini menyiratkan keajaiban ilmiah yang sangat penting [5].

Purwanto menyatakan bahwa ketika al Qur'an turun, ide atomos Democritus telah berumur sekitar sepuluh abad, meskipun mungkin belum dikenal di tanah Arab. Artinya, saat itu ide serbuk superhalus dari logam telah berkembang. Dengan keberadaan ide ini, sebenarnya tidak ada masalah untuk memahami teks secara harfiah, 'dan Kami telah menurunkan serbuk besi'. (2015:284). Pertanyaan yang kemudian muncul adalah, serbuk besi tersebut diturunkan darimana, kapan, bagaimana, mengapa serta pertanyaan epistimologi lainnya yang lahir dari teks wahyu. Untuk itu banyak jalur ilmu pengetahuan yang harus ditempuh agar pertanyaan-pertanyaan tersebut bisa terjawab.

Sains modern memberikan informasi bahwa besi yang merupakan logam berat yang tidak dapat dihasilkan oleh bumi sendiri atau oleh planet lain. Bahkan seluruh energi matahari tidak cukup untuk membentuk satu atom besi. Dalam perhitungan, untuk membentuk satu atom besi $(\mathrm{Fe})$ diperlukan sekitar empat kali sebanyak sistim energi matahari seluruhnya. Besi hanya dapat dihasilkan di dalam bintang-bintang yang jauh lebih besar dari matahari, yang suhunya mencapai beberapa ratus juta derajat. Ketika jumlah besi telah melampaui batas tertentu dalam sebuah bintang, bintang tersebut tidak mampu lagi menanggungnya dan akhirnya meledak melalui peristiwa yang disebut supernova. Akibat ledakanan ini meteor-meteor yang mengandung besi bertaburan di seluruh alam semesta dan bergerak melalui ruang hampa sampai ditarik gaya gravitasi benda angkasa pada masa awal terbentuknya bumi [5].

Maka sangat sesuai ketika Allah berfirman 'wa-anzalna al-hadiida ' yang artinya 'dan kami turunkan besi'. Al Qur'an telah menggunakan kata-kata yang tepat dan mudah dipahami, akan tetapi karena keterbatasan akal pikiran maka mayoritas mufassir berpendapat bahwa besi tidak mungkin diturunkan [5] [2]. Disinilah dibutuhkan kajian sains yang dapat membantu mengungkapkan kebenaran Firman Allah swt tersebut.

Point kedua berkaitan dengan besi yang terdapat pada Q.S. Al Hadid (57) : 25 ini adalah berkaitan dengan kalimat fiihi ba'sun syadiidun (padanya terdapat kekuatan yang hebat). Besi memiliki manfaat yang sangat tinggi dalam kehidupan manusia, dari mulai barang rumah tangga, industri sampai peralatan militer.

Kehebatan besi dapat terungkap melalui kebesaran Allah dan bukti kasih sayang terhadap makhlukNya, yaitu Allah telah mendesain bumi yang dilindungi oleh Sabuk Van Allen yang terbentuk dari inti bumi yang besar, yaitu besi dan nikel. Sabuk Van Allen memiliki energi tinggi yang terdiri dari proton dan elektron untuk membungkus bumi dan menjadi perisai berbentuk medan elektromagnetik yang tidak dimiliki oleh planet lain kecuali planet Merkurius dengan radiasi yang lebih lemah. Selain itu, sabuk Van Allen juga melindungi bumi dan isinya dari ledakan dahsyat energi matahari yang terjadi setiap 11 tahun sekali yang disebut solar flares [5], metonic cycle 19 tahun sekali dan komet Halley yang rata-rata 76 tahun sekali mendekati bumi. Ledakan dahsyat ini apabila tidak ditahan di angkasa dapat menghancukan semua kehidupan bumi. Perlindungan juga didapatkan dari serangkaian badai kosmis yang membahayakan umat manusia [2].

Dengan menggali sisi kauniyah besi dan kajian sains kita memahami mengapa besi begitu istimewa, memiliki kekuatan yang hebat dan Allah menjadikannya sebagai salah satu surat dalam al Qur'an.

\section{Besi, Kimia dan Kodetifikasi Bilangan}

Tafsiran terhadap surat mengenai besi akan berkaitan dengan ilmu kimia bahkan keindahan surat alhadid dapat kita ketahui jika kita memahami sifat-sifat besi [2].

Pertama,

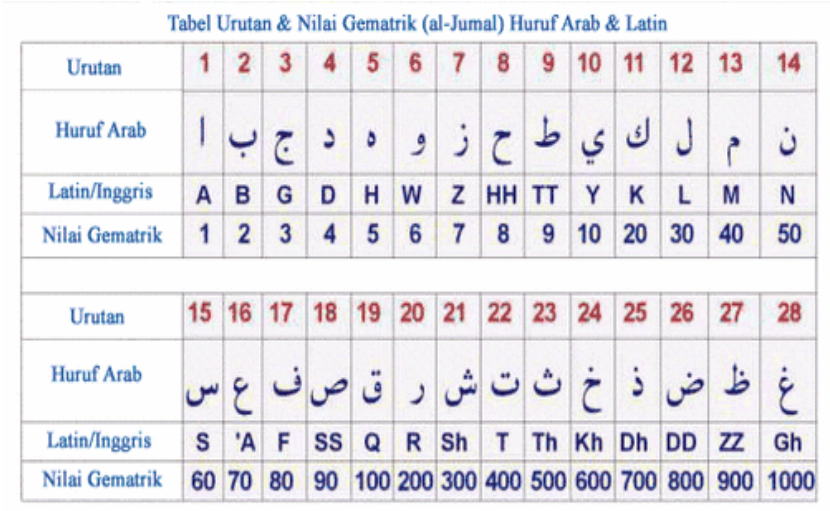

Gambar 1. Tabel Urutan dan Nilai Gematrik (al Jumal) Huruf Arab dan Latin 
Alhadid memiliki nilai kata atau $\mathrm{Al}$-jumal 57. Dapat dilihat dalam tabel di bawah bahwa secara jumlah Huruf terdiri dari " $\mathrm{Al}=(31)$ " dan "hadid $=26 "$.

Alif $=1, \mathrm{Lam}=30, \mathrm{Ha}^{\prime}=8, \mathrm{Dal}=4, \mathrm{Ya}^{\prime}=10, \mathrm{Dal}$ $=4$

$1+30+8+4+10+4=31+26=57$

Nilai al Jumal 57 Alhadid ini sama dengan nomor suratnya atau $(19 \times 3)$. Kelipatan 19 dengan koefisien angka 3. Besi atau Fe memiliki 8-isotop dan 4 tingkatan energi, sehingga 4-isotop saja yang stabil, yaitu dengan simbol Fe-54, Fe-56, Fe57 , dan Fe-58.

Tabel 1. Isotop Besi

\begin{tabular}{cccc}
\hline Isotop & Waktu Paruh & Isotop & Waktu Paruh \\
\hline Fe-.52 & 8.3 jam & FP-57 & Stabil \\
Fe-54 & Stabil & Fe-58 & Stabil \\
Fe-55 & 2.7 tahun & Fe-59 & 54.5 hari \\
Fe-56 & Stabil & Fe-60 & 1.500 .000 tahun \\
\hline
\end{tabular}

(http://www.chemicalelements.com/elents/fe.htm)

Besi mempunyai nomor atom-26, posisinya terletak di tengah-tengah tabel periodik. Fe-57 merupakan salah satu isotop besi yang stabil dan mempunyai 31 neutron. Isotop stabil lainnya adalah Fe-56 mempunyai 30-neutron dan $\mathrm{Fe}-58$ mempunyai 32-neutron. Fe-57 juga mempunyai Massa Atom sebesar 56,9354 dan ionisasi energi tingkat ke-3, sebesar $2957 \mathrm{Jk} / \mathrm{mol}$ (dibulatkan), energi yang keluar untuk mengubah status $\mathrm{Fe}^{+2} \mathrm{ke}$ $\mathrm{Fe}^{3+} \quad$ (http://environmentalchemistry.com/yogi/ periodic/Fepg2.html/\#57) [2].

Kedua,

Mufti menyebutkan bahwa besi memiliki beberapa karakterisitik yaitu:

1. Fe-57 mempunyi Elektron-31 buah, ditunjukkan oleh Al-jumal dari kata al.

2. Besi mempunyai nomor atom -26, ditunjukkan oleh Al-jumal kata hadid.

3. Salah satu isotop besi yang stabil, $\mathrm{Fe}-57$, mempunyai nomor simbol yang sama dengan nomor Surat al-Hadid dan Tabel Al-jumal dari Alhadid yaitu 57.

4. Koefisien 3, dari $(19 \times 3)$, ditunjukkan dengan ionisasi tinkat energi ke-3 yang dilepas sebesar $2957 \mathrm{jk} / \mathrm{mol}$.

5. Bila kodetifikasi 2957dikonversi ke numerik Al-Qur'an maka Surat Al-Hadid [57] terdiri 29 Ayat.

6. Surat alhadid memiliki 574 kata, sedangkan banyaknya kata dari awal surat sampai dengan ayat ke-25 (kata pertama) adalah 451. Bilangan 574 menunjukkan "Fe-57 adalah salah satu isotop yang stabil dari 4-isotop yang ada dan berarti mempunyai 4-tingkatan energi.

7. Bilangan 451, banyaknya kata, adalah jumlah bilangan nomor simbol 8-isotop besi:Fe-52, Fe-54, Fe-55, Fe56, Fe-57, Fe58 , Fe-58, sampai Fe-60; yaitu $52+54+$ $55+56+57+58+59+60=451$.

8. Enkripsi pada 4-isotop stabil, Fe-54, Fe56, Fe-57, dan Fe-58 merupakan kelipatan-19 atau: $54565758=19 \mathrm{x}$ 2871882

9. Massa atom Fe-57, 56.9354 adalah : $569354=19 \times 29966$

10. Nomor surat dan nomor ayat besi (QS 57: 25) ditunjukkan dengan angka-19. $>5+7+2+5=19$.

11. Surat "Al-Hadid" diletakkan di tengahtengah "Al-Qur'an", sebagaimana Elemen Besi nomor 26 terletak di tengah-tengah "Tabel Periodik".

12. Dari sisi matematika, angka 57 dan 29 adalah ajaib karena angka-angka tersebut merupakan: $57 \times 29=1+2+3+4+5+6$ $+\ldots+57$ atau $(19 \times 87)$ [2].

\section{Daud dan Zulkarnain}

Bila meninjau kembali QS. 57:25 yang menyebut tentang besi, maka umat Islam dihadapkan pada suatu konsekuensi bagaimana seharusnya menyikapi tentang keistimewaan besi berupa "kekuatan yang hebat dan berbagai manfaat bagi manusia", yaitu "..(supaya mereka mempergunakan besi itu) dan supaya Allah mengetahui siapa yang menolong (agama) Nya dan rasul-rasulNya padahal Allah tidak dilihatnya".

Dalam Al Quran disebutkan bahwa Daud dan Zulkarnain adalah dua orang shaleh yang menguasai ilmu dan teknologi besi. Beberapa makna dalam penggunaan besi tersebut adalah sebagai alat pertahanan yang mereka gunakan untuk menegakkan ajaran tauhid. Mereka memiliki kesamaan dalam teknologi pengolahan logam (metalurgi) besi dan sedikit perbedaannya yaitu Daud memperoleh karunia dari Allah berupa kemampuan menganyam besi untuk baju perang [1].

Dalam surah Al-Anbiya ayat 80, diterangkan, "Dan, Kami ajarkan kepada Daud membuat baju besi untuk kamu gunakan memelihara kamu dalam peperanganmu. Maka, hendaklah kamu bersyukur (kepada Allah)."

Kemudian, dalam surah Saba' ayat 11, Daud diperintahkan membuat baju perang yang terbuat dari besi. "(Yaitu) buatlah baju besi yang besar-besar dan ukurlah anyamannya dan 
kerjakanlah amalan yang saleh. Sesungguhnya, Aku melihat apa yang kamu kerjakan." Secara tegas, ayat tersebut memberikan contoh cara membuat baju perang dari besi.

Dalam buku Atlas Sejarah Nabi dan Rasul, al-Magluts (2008), menyebutkan bahwa Nabi Daud AS diperkirakan hidup pada tahun 1041-971 SM dan merupakan manusia pertama yang pernah membuat baju dari besi [6].

Kemampuan yang dimiliki Nabi Daud dalam melunakkan besi ini berbeda dengan yang dilakukan Zulkarnain pada abad ke-6 SM (545 SM). Dalam surah Alkahfi (18) ayat 96:

(Ditegaskan bahwa Zulkarnain berkata), "Berilah aku potongan-potongan besi." Apabila besi itu telah sama rata dengan kedua (puncak) gunung itu, berkatalah Zulkarnain, "Tiuplah (api itu)." Apabila besi itu sudah menjadi (merah seperti) api, dia pun berkata, "Berilah aku tembaga (yang mendidik) agar aku tuangkan ke atas besi panas itu."

Dalam ayat tersebut termuat sejarah yang memaparkan garis besar proses suatu teknologi, yaitu Zulkarnain yang berusaha menyelamatkan penduduk dari gangguang Ya'juj dan Ma'juz dengan cara membangun dinding kokoh di celah antara dua dinding tinggi.

Purwanto menyatakan bahwa ayat ini menggambarkan teknik dan proses tertentu, yaitu teknik pengecoran lengkap dengan bahan dasarnya. Teknik yang digambarkan ayat ini memuat dua unsur atau bahan : alhadid dan qithrun, dua keadaan, sawa baina al shadafaini dan narun, serta dua proses: anfakhu dan ufrigh. Tujuan pengecoran, dalam kasus ayat ini, memperoleh logam paduan besi tembaga yang lebih kuat daripada logam besi murni dan kokoh sebagai benteng pembatas dusun [4].

\section{Mengatasi Korosi Besi Secara Kimiawi}

Besi selain memiliki banyak kehebatan, keunikan dan kemanfaatan yang besar bagia manusia seperti disebutkan di atas, kita juga mendapatkan kenyataan bahwa besi memiliki satu kelemahan yaitu mudah terkena korosi atau karat. Hal ini menjadi suatu tantangan bagi manusia agar mengembangkan akal pikirannya untuk mengatasi salah satu kelemahan besi ini. Berikut hasil analisa secara kimiawi untuk mengantisipasi korosi pada besi.

Dari hasil analisis pengukuran elektrokimia dengan metode ekstrapolasi Tafel, maka akan diperoleh aluran Tafel yang menunjukkan laju korosi baja karbon dalam larutan $\mathrm{NaCl} 1 \%$ jenuh $\mathrm{CO}_{2}$ dengan dan tanpa inhibitor. Data analisis tersebut akan menggambarkan pengaruh konsentrasi inhibitor terhadap laju korosi dan jenis inhibitornya.

\section{Jenis Inhibitor}

Pada Gambar 2 yang menggambarkan aluran Tafel dalam kondisi dengan dan tanpa inhibitor dengan konsentrasi tertentu, yang dapat memberikan gambaran tentang jenis inhibitor serta efektifitasnya.Jika potensial korosi bergeser ke arah positif setelah ditambahkan inhibitor, maka inhibitor tersebut termasuk jenis inhibitor anodik.Jika potensial korosi bergeser ke arah yang lebih negatif setelah ditambahkan inhibitor, maka inhibitor tersebut termasuk inhibitor katodik. Jika potensial korosi bergeser ke arah yang lebih positif dan negatif, seiring dengan bertambahnya konsentrasi inhibitor, maka inhibitor tersebut termasuk jenis inhibitor campuran (mixed/ohmik) [7].

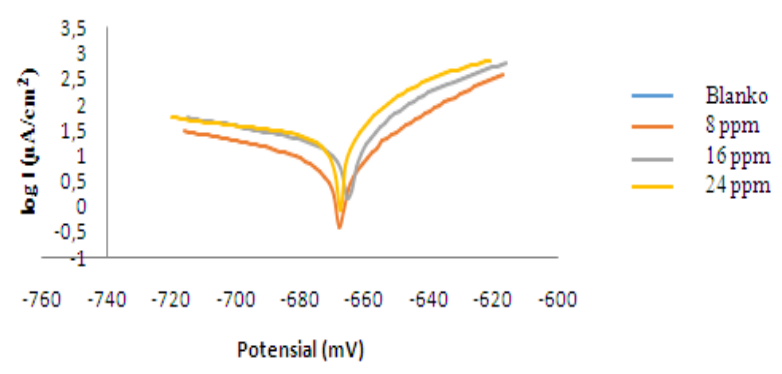

Gambar 2. Aluran Tafel sebelum dan sesudah penambahan inhibitor senyawa 2,3-difenil-imidazo[1,2a]piridin dalam larutan elektrolit jenuh karbon dioksida pada suhu $25^{\circ} \mathrm{C}$.

Pada Gambar 2 terlihat bahwa penambahan inhibitor mengakibatkan pergeseran potensial ke arah yang lebih positif dan negatif. Dilihat dari pergeseran kurva peningkatan konsentrasi tidak menunjukkan perubahan yang signifikan sehingga senyawa 2,3-difenil-imidazo[1,2-a]piridin dapat dikategorikan sebagai inhibitor katodik dan anodik atau inhibitor campuran (mixed/ohmik). Senyawa ini artinya mampu menghambat reaksi reduksi dan oksidasi secara sekaligus.

Pengaruh Konsentrasi Inhibitor Terhadap Laju Korosi Pada Suhu $25^{\circ} \mathrm{C}$

Metode Ekstrapolasi Tafel menunjukkan pengaruh penambahan inhibitor terhadap laju korosi baja karbon dalam lingkungan korosif yaitu $\mathrm{NaCl} 1 \%$ jenuh $\mathrm{CO}_{2}$. 


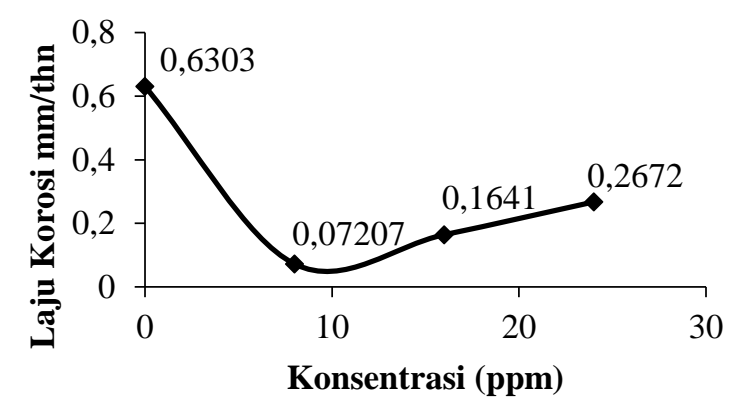

Gambar 3. Pengaruh konsentrasi senyawa 2,3-difenilimidazo[1,2-a]piridin terhadap laju korosi baja karbon pada suhu $25^{\circ} \mathrm{C}$ dalam larutan $\mathrm{NaCl} 1 \%$ jenuh $\mathrm{CO}_{2}$.

Pada Gambar 3 terjadi penurunan laju korosi dari awal setelah penambahan inhibitor. Terjadi penurunan laju korosi yang optimum pada konsentrasi $8 \mathrm{ppm}$ dan kemudian meningkat kembali. Ini terjadi karena adsorpsi inhibitor telah mencapai keadaan jenuh sehingga tidak dapat melindungi permukaan baja karbon, tetapi lebih tertarik pada media dan tersolvasi dalam media setelah itu dapat terjadi desorpsi inhibitor kembali dari permukaan logam yang dapat meningkatkan laju korosi [8].

Pada awal reaksi, peristiwa adsorpsi inhibitor lebih dominan dibandingkan dengan peristiwa desorpsi, sehingga berlangsung lebih cepat dan laju korosi menurun. Setelah tercapai kesetimbangan, laju desorpsi biasanya lebih cepat karena berbagai faktor sehingga laju korosi meningkat. [9].

Pengaruh Konsentrasi Inhibitor Senyawa 2,3difenil-imidazo[1,2-a]piridin terhadap Efektifitas Inhibitor Pada Suhu $25^{\circ} \mathrm{C}$

Pada Gambar 4 menunjukkan pengaruh konsentrasi inhibitor dari senyawa 2,3-difenilimidazo[1,2-a]piridin terhadap efektifitas inhibitor pada suhu $25^{\circ} \mathrm{C}$. Semakin tinggi nilai efesiensi inhibisi, maka akan semakin baik efektifitas inhibisi korosi pada senyawa tersebut. [10]

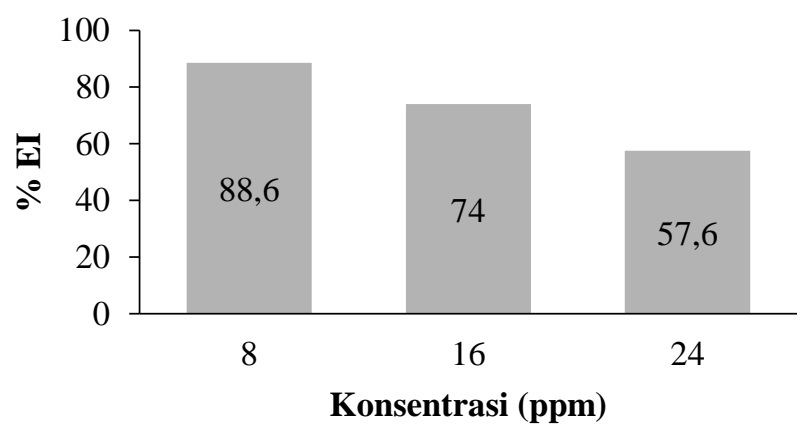

Gambar 4. Pengaruh konsentrasi inhibitor dari senyawa 2,3-difenil-imidazol]1,2-a]piridin terhadap efektifitas inhibitor pada suhu $25^{\circ} \mathrm{C}$
Senyawa yang memiliki struktur berbasis imidazole teradsorpsi pada bagian katoda dan melindungi besi dari reduksi ion $\mathrm{H}^{+}$. Ikatan $\mathrm{C}=\mathrm{N}$ yang terdapat pada cincin imidazol mampu membentuk ikatan phi dengan mendonorkan elektron phi ke orbital kosong yang terdapat pada Fe. Selain itu orbital phi bintang pada cincin imidazol juga dapat menerima elekton dari orbital $\mathrm{d}$ dari $\mathrm{Fe}$ sehingga akan membentuk pusat adsorpsi yang baru. Terlihat pada gambar 4.6 bahwa senyawa 2,3-difenil-imidazo[1,2-a]piridin dapat menurunkan laju korosi pada konsentrasi 8 ppm dengan efisiensi inhibisi sebesar 88,6\%, karena pada senyawa 2,3-difenil-imidazo[1,2a]piridin terdapat suatu gugus heteroatom pendorong elektron yang dapat menyediakan pasangan elektron pada sistem elektron phi sehingga meningkatkan interaksi dengan permukaan logam besi (Fe) [7].

Dilihat dari struktur molekul senyawa 2,3difenil-imidazo[1,2-a]piridin yang planar sehingga sangat memungkinkan memiliki aktifitas inhibisi korosi yang baik dan sangat potensial dikembangkan sebagai inhibitor korosi karena mengandung gugus fungsi elektronegatifdan memiliki elektron phi pada ikatan rangkap terkonjugasi yang umumnya merupakan syarat inhibitor korosi yang baik [11]. Serta senyawa tersebut mengandung atom $\mathrm{N}$ yang memiliki pasangan elektron bebas yang dapat mengadsorpsi pada permukaan logam sehingga dapat menginhibisi dengan baik [7].

\section{Pengaruh Suhu terhadap Efektifitas Inhibitor}

Pada Gambar 5 menunjukkan pengaruh suhu inhibitor terhadap efektifitas inhibitor dalam larutan elektrolit jenuh karbon dioksida dengan penambahan $8 \mathrm{ppm}$ senyawa 2,3-difenilimidazo[1,2-a]piridin.

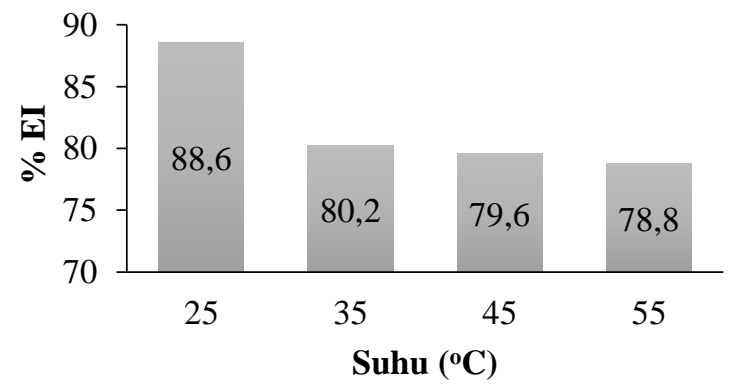

Gambar 5. Pengaruh suhu terhadap efektifitas inhibitor dalam larutan elektrolit jenuh karbon dioksida dengan penambahan $8 \mathrm{ppm}$ senyawa 2,3-difenilimidazo[1,2-a]piridin

Terlihat pada Gambar 5 bahwa efisiensi inhibitor menurun dengan naiknya suhu, efisiensi inhibisi dengan penambahan 8 ppm senyawa 2,3- 
difenil-imidazo[1,2-a]piridin sebesar 88,6\% pada suhu $25^{\circ} \mathrm{C}$. Hal ini disebabkan dengan meningkatnya suhu maka pelarutan logam makin meningkat dan terjadinya desorpsi inhibitor dari permukaan logam. Suhu tinggi dapat meningkatkan energi kinetik yang akan mengakibatkan lapisan inhibitor akan lebih mudah terkelupas. Peningkatan temperatur cenderung menurunkan kekuatan reaksi antara atom-atom $\mathrm{Fe}$ dengan gugus fungsi aktif dalam inhibitor, sehingga kemampuan inhibisi inhibitor pada korosi baja karbon cenderung menurun. Hal ini berdampak pada peningkatan ion-ion $\mathrm{Fe}^{2+}$.

\section{Isoterm Adsorpsi}

Pengaruh inhibitor terhadap laju korosi dapat ditentukan oleh isoterm adsorpsi utamanya disebabkan karena adanya adsorpsi pada permukaan logam.Isoterm adsorpsi dapat memberikan informasi tambahan tentang sifatsifat inhibitor.Isoterm adsorpsi yang mudah ditentukan dan biasa digunakan dalam menentukan sifat adsorpsi diantaranya isoterm Langmuir dan isoterm adsorpsi Temkin.Fraksi permukaan yang tertutupi oleh inhibitor $\theta$ ditentukan dengan perbandingan $\mathrm{EI}(\% / 100)$ [3] Mekanisme inhibisi dari inhibitor korosi senyawa 2,3-difenil-imidazo[1,2-a]piridin ditentukan dengan menghitung fraksi permukaan yang tertutupi $\theta$.

Data yang diperoleh menunjukkan bahwa senyawa 2,3-difenil-imidazo[1,2-a]piridin menghasilkan plot linier pada kurva isoterm adsorpsi Langmuir, dengan $\mathrm{R}^{2}=0.9822$. Isoterm Langmuir didasarkan pada asumsi bahwa setiap tempat adsorpsi adalah ekuivalen, dan kemampuan partikel untuk terikat di tempat tidak bergantung pada ditempati atau tidaknya tempat yang berdekatan [12].

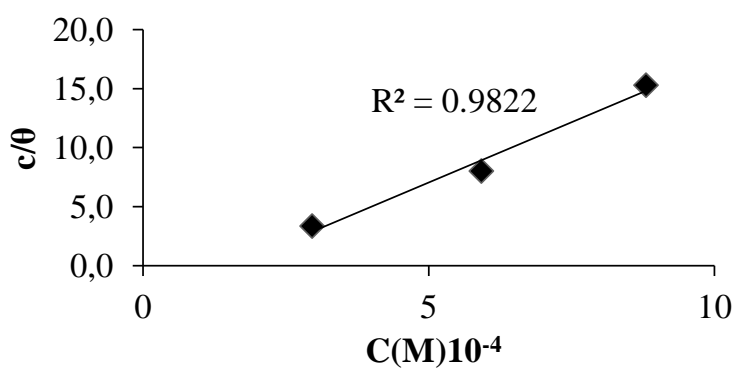

Gambar 6. Kurva isoterm adsorpsi Langmuir senyawa 2,3-difenil-imidazo[1,2-a]piridin

Senyawa 2,3-difenil-imidazo[1,2-a]piridin selain menghasilkan plot linier pada kurva isoterm Langmuir, senyawa ini juga menghasilkan blok linier pada kurva isoterm adsorpsi Temkin dengan $\mathrm{R}^{2}=0.9644$.

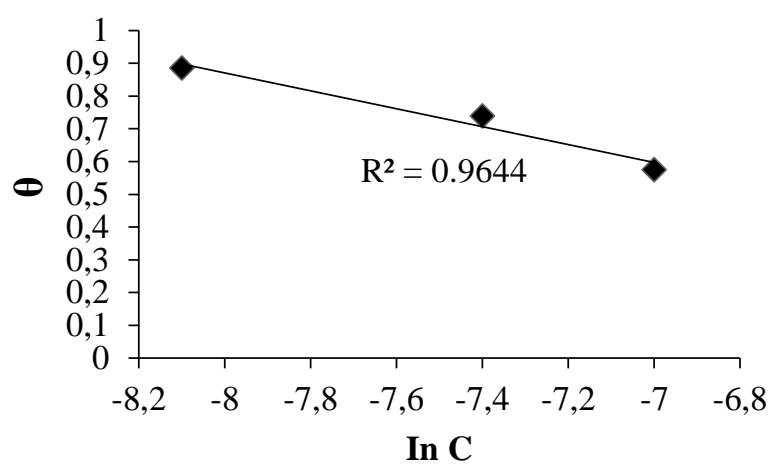

Gambar 7 Kurva isoterm adsorpsi Temkin senyawa 2,3-difenil-imidazo[1,2-a]piridin

Isoterm Temkin menganggap adsorpsi pada semua molekul pada permukaan akan menurun linier dengan interaksi antara adsorbat dan adsorben [13]. Entalpi adsorpsi sering menjadi kurang negatif saat $\theta$ bertambah, hal ini menunjukkan bahwa tempat yang paling menguntungkan dari segi energinya, akan ditempati lebih dahulu [12]. Berdasarkan kedua kurva adsorpsi isoterm di atas, nilai regresi linier $\left(\mathrm{R}^{2}\right)$ yang paling besar adalah kurva adsorpsi isoterm Langmuir yang bernilai 0,9822 dibandingkan dengan nilai regresi linier $\left(\mathrm{R}^{2}\right)$ yang bernilai 0,9644. Maka mekanisme senyawa 2,3difenil-imidazo[1,2-a]piridin mengikuti isoterm adsorpsi Langmuir karena nilai regresi liniernya mendekati 1.Isoterm adsorpsi Langmuir didasarkan atas beberapa asumsi,yaitu adsorpsi hanya terjadi pada lapisan tunggal (monolayer) pada permukaan baja dan terjadi adsorpsi elektrostatis, panas adsorpsi tidak tergantung pada penutupan permukaan, dan semua situs dan permukaannya bersifat homogen [13]. Aktivitas inhibitor senyawa 2,3-difenil-imidazo[1,2a]piridin menunjukkan kesesuaian dengan isoterm Langmuir yaitu dengan membentuk lapisan monolayer pada permukaan baja. Langmuir manggambarkan hubungan antara fraksi permukaan yang tertutupi karena adsorpsi dengan konsentrasi adsorbat dalam larutan.

\section{SIMPULAN}

Dari hasil penelitian disimpulkan bahwa dengan menggali sisi kauniyah besi dan kajian sains kita memahami mengapa besi begitu istimewa dan menempati salah satu surat dalam al Qur'an, selain terungkapnya realitas ilmiah bahwa besi memang 'diturunkan'. Kehebatan besi juga terungkap, diantaranya inti besi bersama nikel melindungi makhluk bumi dengan perisai elektromagnetik dengan 'kekuatan yang hebat'.

Senyawa 2,3-difenil-imidazo[1,2-a]piridin merupakan inhibitor campuran. Aktivitas inhibitor 
korosi senyawa 2,3-difenil-imidazo[1,2-a]piridin meningkat dengan naiknya konsentrasi inhibitor kemudian menurun kembali dan mencapai maksimum pada konsentrasi $8 \mathrm{ppm}$. Naiknya suhu dari $25-55^{\circ} \mathrm{C}$ menyebabkan aktivitas inhibisi menurun sehingga efisiensi inhibisi maksimum konsentrasi $8 \mathrm{ppm}$ terdapat pada suhu $25^{\circ} \mathrm{C}$ dengan efisiensi inhibisi $88,6 \%$. Aktivitas inhibitor menunjukkan kesesuaian dengan isoterm Langmuir yaitu dengan membentuk lapisan monolayer pada permukaan baja.

\section{REFERENSI}

[1] Suhendar D, Ilmu Kimia Dalam Kacamata al Qur'an. Pustaka Ilmu: Yogyakarta, 2015.

[2] Muftie A, Matematika Alam Semesta. Bandung: Dasur Basya'ir, 2004.

[3] Yunus H, Tafsir Al Quran Al Karim. Jakarta: PT Hida Karya Agung, 2004.

[4] Purwanto A, Nalar ayat-ayat Semesta. Bandung: Mizan, 2015.

[5] Yahya H, Al Qur'an dan Sains. Bandung: Teladan, 2004.

[6] Al Maghluts, Atlas Sejarah Para Nabi \& Rasul, Menggali Nilai-Nilai Kehidupan Para Utusan Allah. Jakarta: Almahira, 2008.

[7] B Bundjali, "Perilaku dan Inhibisi Korosi Baja Karbon dalam Larutan Buffer Asetat,
Bikarbonat- $\mathrm{CO}_{2 ., "}$ Bandung, Disertasi 2005.

[8] Fitriasih S, "Studi Inhibisi Korosi Baja 304 Dalam HCL 2 M dengan Inhibitor Campuran Asam Lemak Hasil Hidrolisa Minyak Biji Kapuk," Jurnal Jurusan Kimia FMIFA ITS, 2010.

[9] Sukarta I N, "Adsorpsi Ion $\mathrm{Cr}^{3+}$ Oleh Serbuk Gergaji Kayu Albizia," 2008.

[10] Munazim I. F, "Sintesis 2-fenil-4,5di(2piridil) imidazole, 2-fenil-4,5-di(2piridil)oksazol, dan 2-(2-hidroksifenil)4,5di(2-piridil)imidazole Sebagai Inhibitor Korosi Pada Baja Karbon," Bandung, Tesis 2009.

[11] Elayyachy M, El Koldadi, M Hammouti, B Ramdani, and A Elidrissi, "Characterization of New Tripyrazole Derivate as Inhibitor for the Steel Corrosion in Acid Solution," Pigment \& Resin Technology, 2004.

[12] P. W Atkins, Kimia Fisik Jilid 2. Jakarta: Erlangga, 1996.

[13] Sukarta I N, "Adsopsi Ion $\mathrm{Cr}^{3+}$ Oleh Serbuk Gergaji Kayu Albizia (Albizia Falcata): Studi Pengembangan Bahan Alternatif Penyerapan Limbah Logam Berat," Bogor, Tesis 2008. 